P67 (continued)

$(7.87 \pm 2.46)$. Mean cooking self-efficacy scores also improved significantly $(P=.002)$ from baseline $(13.75 \pm$ $4.50)$ to program exit $(11.53 \pm 3.88)$.

Conclusion: Flint Kids Cook could be modeled in similar communities to engage children and promote positive changes in cooking attitudes and self-efficacy.

Funding: Michigan Health Endowment Fund.

\section{P68 FSU Cooks: Culinary Nutrition Workshops Help Participants Learn About Food, Cook, and Eat!}

\author{
Catherine Wickham, PhD, RDN, CD-N, \\ cwickham@framingham.edu, Framingham State \\ University, Department of Food and Nutrition, 100 State \\ St, PO Box 9101, Framingham, MA 01701; Jerusha Nelson- \\ Peterman, PhD, RD, Framingham State University, \\ Department of Food and Nutrition; Ann Johnson, PhD, \\ $L D N, R D, M B A$, Framingham State University, \\ Department of Food and Nutrition
}

Objective: FSU Cooks: Learn.Cook.Eat was developed by the Food and Nutrition Department (FND) at Framingham State University (FSU). The purpose of the program is to provide an educational environment focused on food and culinary literacy. Participants learn about food, participate in hand-on cooking, and eat their creations. The aim of the pilot was to assess the feasibility of offering the program to community members.

Use of Theory or Research: There is increasing evidence that hands-on culinary experiences can empower people to make healthy food choices by increasing exposure to new foods and techniques and increasing selfefficacy.

Target Audience: FSU students and Framingham community members.

Program Description: FSU Cooks was piloted during Fall 2018 with two introductory campus and community lectures and three culinary nutrition workshops focused on diet and brain health. Lectures provided a backdrop to the workshops which targeted 'brainy' foods: whole grains, dark-green leafy vegetables, and spices. Workshop were led by FND faculty and FSU's executive chef. In addition, students from the FND acted as culinary assistants. Each workshop included an overview of nutrition-related topics, cooking demonstrations, and hands-on culinary experiences.

Evaluation Methods: Workshop activities were assessed using process evaluation. Participants rated questions on a scale ( $5=$ strongly agree and $1=$ strongly disagree). Qualitative data about the workshop was also collected.

Results: Twenty one participants attended three workshops. All participants indicated that they strongly agreed or agreed that the workshop information was useful and they would recommend the program to family and friends.

Conclusions: Hands-on culinary workshops can be a fun and engaging way for participants to become empowered to make healthy choices. Based on information learned from the pilot, plans are in place to continue programing in spring 2019 with a focus on heart healthy foods. Additional evaluation methods will be incorporated to assess changes in participants pre-/post-workshop knowledge and intentions to change eating practices.

Funding: Framingham State University.

\section{P69 Fun with Fresh Food Rainbow Nutrition Program Helps Families Improve Attitudes and Behavior Around Fruits and Vegetables}

MaryBeth Hornbeck, MS, BS, marybeth.hornbeck@uga.edu, University of Georgia Cooperative Extension, 1261 Commercial Dr, Conyers, GA 30094; Alison Berg, PhD, LD, $R D N$, University of Georgia Cooperative Extension; Roxie Price, MS, BS, University of Georgia Cooperative Extension

Objective: The Fun with Fresh Food (FFF) Rainbow Nutrition program is designed for families to improve attitudes and behaviors around fruit and vegetable (FV) consumption. This includes improving self-efficacy in adults preparing and serving $\mathrm{FV}$, and increased interest in cooking and willingness to try FV in children.

Use of Theory or Research: Previous research suggests parental self-efficacy around food affects children's diet quality. Social Cognitive Theory suggests modeling of food preparation is effective at increasing self-efficacy. Additionally, studies show children may need 10 to 30 exposures to foods before accepting them.

Target Audience: Children (ages 2-13) and their parents/guardians attending summer community events in suburban Georgia in 2018.

Program Description: FFF uses research-based techniques for addressing picky eating in a six-week series of 20minute interactive rainbow-themed food "commercials." Each week centers on a color (i.e. purple), with the specific food (i.e. cabbage) remaining unknown until sessions begin. Children participate in age-appropriate kitchen tasks as part of a recipe demonstration. Sessions include taste tests and produce giveaways.

Evaluation Methods: Weekly post-program parent surveys assessed knowledge and behavioral intention. A final post-survey assessed parents' perceived impact of series overall. Nine parents with $>50 \%$ attendance participated in interviews and focus groups to further explore program impact and acceptability.

Results: Average weekly attendance was 110 people; 50 children attended $\geq 50 \%$ of sessions. Eighty-three percent of adults gained FV knowledge and 78\% intended to incorporate a recipe or tactic at home. Focus group data showed increased confidence in serving FV, greater interest in children cooking and eating FV, and the rainbow theme being a significant draw.

Conclusions: The FFF program suggests short, repeat exposure to FV can have a strong impact on parental self-efficacy for cooking and eating FV and child interest in FV. Short demos may reduce barriers by illustrating healthy eating does not have to be time consuming or difficult. The FFF model could be employed in many 
P69 (continued)

community settings to reach families in a whimsical yet substantive way.

Funding: None.

\section{P70 Hands-0n Culinary Education Program for Youth Improves Cooking Skills, Attitudes, Self- Efficacy, Behaviors, and Food Preferences}

Jessica Metcalfe,PhD, MPH, jarick2@illinois.edu, University of Illinois at Urbana-Champaign, 905 S Goodwin Ave, MC-182, Urbana, IL 61853; Barbara Fiese, PhD, University of Illinois at Urbana-Champaign; Jennifer McCaffrey, PhD, MPH, RD, University of Illinois at UrbanaChampaign

Objective: Evaluate the impact of a revised version of the Illinois Junior Chefs (IJC) program using pre- and postintervention surveys and observational assessments of hands-on cooking skills.

Use of Theory or Research: To date, evaluations of nutrition education and cooking programs in youth have been limited to self-reported assessments of cooking skills. Along with using an established IJC survey, this study developed a novel observational protocol to assess handson cooking skills in youth.

Target Audience: Supplemental Nutrition Assistance Program - Education (SNAP-Ed) eligible youth $(\mathrm{n}=591)$ aged 8-13.

Program Description: IJC is a hands-on culinary and nutrition education program implemented by the University of Illinois Office of Extension and Outreach. IJC is taught over five 2-hour lessons which include nutrition education, culinary skill building activities, recipe preparation, and food tastings.

Evaluation Methods: Pre- and post-intervention evaluations assessed hands-on cooking skills (observational assessment, $\mathrm{n}=37$ ) and psychosocial predictors of dietary behaviors (IJC survey, $\mathrm{n}=591$ ).

Results: Analyses of surveys indicated participants experienced significant improvements pre- to post-intervention in cooking self-efficacy $(\mathrm{t}(590)=18.63, P<.001)$, cooking attitudes $(\mathrm{t}(590)=7.12, P<.001)$, fruit and vegetable preferences $(\mathrm{t}(590)=5.81, P<.001)$, and cooking behaviors $(\mathrm{t}(590)=3.38, P=.001)$. Pre- to post-intervention analyses of observational data indicated participants experienced significant improvements in their ability to use a peeler $(\mathrm{t}(36)=5.11, P<.001)$, use a grater $(\mathrm{t}$ $(36)=5.62, P<.001)$, beat $(\mathrm{t}(36)=5.05, P<.001)$ and fold $(\mathrm{t}(36)=6.67, P<.001)$ ingredients, measure water $(\mathrm{t}$ $(36)=2.47, P=.018)$, sugar $(\mathrm{t}(36)=4.02, P<.001)$, and flour $(\mathrm{t}(36)=7.07, P<.001)$, and crack eggs $(\mathrm{t}(36)=2.70$, $P=.010)$.

Conclusions: IJC participants experienced significant improvements in cooking self-efficacy, attitudes, behaviors, and food preferences. The observational assessment was established as a feasible data collection method which demonstrated significant improvements in youth participants' cooking skills.

Funding: SNAP-Ed, USDA, EFNEP, 4-H Foundation.

\section{P71 Healthy Habits for Life: Food-Tastic Youth Programs to Build Healthy Relationships with Food}

Vanessa Spero, MS, BS, Vspero@ufl.edu, University of Florida IFAS Extension, 3695 Lake Dr, Cocoa, FL 32926; Shephard Elizabeth, BS, MPA, University of Florida IFAS Extension; Whitworth Gayle, BS, MPA, University of Florida IFAS Extension; Lazzari Andrea, MS, BS, University of Florida IFAS Extension; Keene Angelika, BA, University of Florida IFAS Extension

Objective: To empower school-aged, at-risk youth and their families with the knowledge and skills needed to make healthier choices resulting in positive behavior changes using agriculture, nutrition, and health education.

Use of Theory or Research: Many families don't have access to quality food and nutrition education and are at risk of negative health outcomes including inadequate nutrition and physical activity, leading to obesity and various other diseases (Choi, 2007; Stuart et al, 2008; Valois et al, 2002).

Target Audience: School-aged, at-risk youth and their families.

Program Description: Three unique programs offered at schools, over the summer, and within the community: Try It Tuesday, a monthly program held in public elementary schools that gives students the opportunity to try a new fruit or vegetable and is occasionally incorporated into the cafeteria's menu, Tiny Market, a mobile farmer's market brought to summer-camp sites to educate youth on where food comes from and nutrition through activities such as scavenger hunts, healthy snack preparation, and shopping at the market, and Farmers in Training (F.I. T.), a program held at our monthly farmers market where children complete a taste test, physical activity, and nutrition activity focused on an in-season fruit or vegetable for 'Farmer's Market Bucks' to shop at the market.

Evaluation Methods: Program outcomes are evaluated through pre- and post-surveys.

Results: These evaluations have shown that youth exhibited a 55\% knowledge gain about the importance of healthy food choices. Youth increased their awareness of fruit consumption by $12 \%$ and their vegetable consumption by $10 \%$. In addition, $9 \%$ of youth began giving their family suggestions on healthy snacks and meals.

Conclusions: These results suggest that youth who explore relationships with foods are empowered to immediately incorporate healthy choices into their lifestyle.

Funding: University of Florida, IFAS, Extension.

\section{P72 Impact of a Community Cooking Program on Self-Efficacy and Usage of Healthy Foods}

Joanna Rebitski, joannarebitski@gmail.com, University of Cincinnati, 2600 Clifton Ave, Cincinnati, OH 45220; Jamie Stoneham, FarmChef Services, LLC; Stacey M. Gomes, MS, Cincinnati Children's Hospital Medical Center \& University of Cincinnati, College of Criminal Justice, Education and Human Services; Lori E. Crosby, PsyD, 